\title{
The impact of being homeless on the unsuccessful outcome of treatment of pulmonary TB in São Paulo State, Brazil
}

\author{
Otavio T. Ranzani ${ }^{1,2^{*}}$, Carlos R. R. Carvalho ${ }^{1}$, Eliseu A. Waldman ${ }^{3}$ and Laura C. Rodrigues ${ }^{2}$
}

\begin{abstract}
Background: Tuberculosis (TB) is a major public health problem requiring complex treatment, the success of which depends on biological, social, and institutional factors. São Paulo State (SPS), in Brazil, has a high TB burden. Because of high socioeconomic heterogeneity and chaotic urbanisation, homelessness might play an important role in the TB burden in SPS. Our aim was to determine the association between homelessness and outcome of treatment of pulmonary TB (PTB) in SPS.
\end{abstract}

Methods: A historical cohort from the routine SPS TB database for 2009-2013 was analysed. The study population was newly diagnosed adult patients with PTB. Homelessness was ascertained at notification or when treatment started. Our outcome was unsuccessful outcome of treatment. We used logistic regression to adjust for potential confounders and multiple imputation for missing data.

Results: We analysed 61,817 patients; 1726 (2.8\%, 95\%Cl 2.7-2.9 \%) were homeless. Homeless patients were concentrated in bigger cities, were more frequently middle-aged males, had black/brown skin colour, and had received less education $(P<0.001$, for all). Alcohol and drug use was three times more frequent in homeless patients (43.2 \% vs $14.4 \%, 30.2 \%$ vs. $9.4 \%, P<0.001$, respectively). HIV testing was less common among the homeless, of whom $17.3 \%$ were HIV positive compared with $8.5 \%$ among the not homeless population $(\mathrm{P}<0.001)$. Microbiologic confirmation was more frequent among the homeless (91.6\% vs. $84.8 \%, P<0.001)$. Unsuccessful outcome of treatment was $57.3 \%$ among the homeless and $17.5 \%$ among the not homeless $(\mathrm{OR}=6.32,95 \% \mathrm{Cl} 5.73-6.97, \mathrm{P}<0.001)$, mainly due to loss to follow-up (39\%) and death (10.5\%). After full-adjustment for potential confounders, homelessness remained strongly associated with lower treatment success (aOR $=4.96,95 \%$ $\mathrm{Cl}$ 4.27-5.76, $\mathrm{P}<0.001)$. HIV status interacted with homelessness: among HIV-infected patients, the aOR was $2.45(95 \% \mathrm{Cl}$ 1.90-3.16, $\left.P_{\text {interaction }}<0.001\right)$. The population attributable fraction for the joint effect of homelessness, alcohol and drug use was almost $20 \%$.

Conclusions: Confirming our hypothesis, homelessness led to a marked reduction in the successful treatment of newly diagnosed pulmonary tuberculosis. Homelessness and associated conditions were important contributors to lack of treatment success in pulmonary tuberculosis in São Paulo. A multifaceted intervention must be implemented to target this vulnerable population.

Keywords: Tuberculosis, Homeless, Treatment outcome, TB

\footnotetext{
* Correspondence: otavioranzani@yahoo.com.br

${ }^{1}$ Pulmonary Division, Heart Institute (InCor), Medical School, University of São

Paulo, Av. Dr. Arnaldo, 455, 2º andar, sala 2144, Post-code 01246903 São

Paulo, Brazil

${ }^{2}$ London School of Hygiene \& Tropical Medicine (LSHTM), Keppel Street,

Room G9a, Post-code WC1E 7HT London, UK

Full list of author information is available at the end of the article
} 


\section{Background}

Tuberculosis (TB) is an ancient infectious disease that poses several challenges from both the individual and the societal perspective [1]. The 2015 World Health Organization (WHO) report estimated 9.6 million new TB cases and 1.5 million TB deaths worldwide [2]. Although improvements in the burden of TB have been observed, several barriers to TB control remain [1-3].

Pulmonary TB (PTB) is the most frequent TB presentation, representing $80-85 \%$ of cases [1]. PTB treatment requires prolonged and complex management [4]. Although there has been research on shorter treatment courses and alternative schemes, their use in clinical practice is still in debate [5]. Several factors influence treatment adherence, from high incidence of adverse drug events, to direct/ indirect associated costs and stigmatization [3, 6-8]. Regarding TB treatment outcomes, some risk factors have been associated with unsuccessful outcome of treatment, such as: age [9-12], male gender [9, 13], race [10], being an immigrant [10], illiteracy [14], malnutrition [12], HIV positivity [9, 12, 14-17], chronic comorbidities $[12,13,18]$, and socioeconomic factors $[12,16]$. Some factors such as diabetes mellitus and smoking have been associated more frequently with relapse, treatment failure, and death [12, 19-21], while drug use and alcohol use were associated with loss to follow-up and death $[15,19]$. Delay in diagnosis and treatment are also fundamental issues [9, 18, 22].

TB has been labelled a disease of poverty and health inequalities [3, 23]. Homelessness is likely to be an extreme life condition, encompassing several vulnerabilities that markedly increase the risk of being infected, having latent TB infection (LTBI) and developing active disease. Indeed, the homeless population has 10 to 85 times higher incidence of LTBI and active TB compared to the general population [24-26]. Homeless patients are also the source of TB outbreaks in shelters [27]. PTB among the homeless is usually highly infectious, due to the high burden of Mycobacterium tuberculosis in their sputum, delayed diagnosis and overcrowding [28]. These facts highlight the importance of a dedicated and multidisciplinary approach to these patients. However, there is a lack of epidemiological studies focusing on TB treatment outcomes in homeless populations [29-31]; few studies have addressed the impact of homelessness on treatment outcomes, and the available data came from high-income countries [25, 26].

Brazil is among the 22 countries with the highest number of TB cases. In 2014, PTB incidence was estimated as 44/100,000 [2]. São Paulo State (SPS) has the highest number of TB cases in Brazil ( 20\%), with an estimated incidence of PTB of 37.7/100,000 in 2013 [32]. Incidence varies among cities according to size, population density and socioeconomic indicators [32-36] with higher incidences observed in bigger, more crowded cities, such as Santos (population 400,000 , incidence of 72.7/ 100,000) and São Paulo city (population 11,000,000, incidence of 46.6/100,000) in 2013 [32]. Poorer areas and vulnerable groups have higher incidences [33, 37], such as four poor districts (incidence 149.0/100,000) in São Paulo city [35]. Treatment success for newly diagnosed PTB cases is around $80 \%$ in SPS, thus not achieving the WHO goal of $85 \%$ treatment success [2, 32, 38]. Although it is the wealthiest state in Brazil, the high socioeconomic heterogeneity and chaotic urbanisation in SPS, may mean that homelessness plays an important role in the TB burden [39].

The aim of this study was to determine the association between homelessness and the unsuccessful outcome of treatment of newly diagnosed PTB patients in SPS from 2009 to 2013. Our hypothesis is that newly diagnosed PTB patients with vulnerable conditions are at higher risk of not achieving treatment success. This study is justified because evaluations of PTB treatment outcomes among the homeless are rare; and a rigorous quantitative evaluation of this topic is missing for emerging countries.

\section{Methods \\ Study site}

The population of Brazil is 200 million, $22 \%$ of whom (41 million) live in SPS [39]. The state has 645 municipalities with distinct characteristics. The Human Development Index (HDI) ranges from 0.639 to 0.862, and within the main city (São Paulo), the HDI ranges from 0.245 to 0.811 . In 2003, a study reported that $27 \%$ of the population of SPS lived in poverty, with marked income inequality (Gini index $=0.45$ ) [39]. In Brazil, TB treatment is fully covered by the public health system. In SPS, following the National TB Program, directly observed therapy (DOT) is recommended for all patients. However, the final decision is shared between patients and multidisciplinary health staff [38]. DOT can bring additional support during treatment, such as food and transport vouchers $[38,40]$. Although the national guidelines strongly recommend DOT for vulnerable groups such as homeless patients, there is no specific campaign to support its use among the homeless.

\section{Study design}

A historical cohort from the routine electronic SPS TB database for 2009-2013 was studied.

\section{Study population}

Newly diagnosed adult patients with PTB only. We included patients aged $\geq 15$ years, who had never been treated for TB or who had taken anti-TB drugs $\leq 1$ month (i.e. new TB cases) [2]. Before 2010, the Brazilian-TB Program 
considered patients treated more than five years earlier as new cases [38]. For the purpose of this study, only the first TB treatment was considered [2]. The "anatomical definition" of PTB from WHO includes patients with PTB associated with extra-pulmonary TB (EPTB) or miliary TB [41-43]. In order to have a homogenous population of new cases, we selected patients with PTB only.

We excluded presumptive TB patients whose diagnosis had changed during the follow-up period (i.e. they were not TB cases). We also excluded cases diagnosed and notified after necropsy (i.e. they would not have received treatment). Although the WHO "cohort definition" [41] includes patients with TB who died for any reason before or after starting treatment, we excluded patients diagnosed at necropsy because the study aim is to evaluate treatment success [11]. Finally, we excluded patients still on treatment at the moment of database acquisition.

\section{Exposure}

A patient was considered homeless if they were without a fixed, regular, and adequate night-time residence at PTB notification or when treatment started. This definition includes individuals who live in emergency shelters/ direct access hostels and those who live in places not meant for human habitation.

\section{Outcome}

We used the 2013 WHO definitions to guide our main treatment outcome definitions [41], and adapted them to the SPS dataset. This classification consists of six outcomes, grouped into treatment success (cured or treatment completed) and unsuccessful outcome of treatment (treatment failure, death, loss to follow-up and not evaluated). We chose "unsuccessful outcome of treatment" as our primary outcome because we planned a pragmatic evaluation of a routine database.

\section{Confounding factors and interactions}

Based on the literature, and on a theoretical framework, we selected potential confounders a priori to be adjusted for in order to obtain adjusted estimates of the impact of homelessness on PTB treatment outcome. Confounding factors included: age, gender, country of birth, race, education level, alcohol and drug use, diabetes mellitus, mental disorder, immunosuppression other than HIV, place of diagnosis, chest $\mathrm{x}$-ray and microbiologic status at diagnosis, initial drug scheme and DOT.

For biological reasons, HIV is a major determinant of TB treatment outcome and we pre-specified that HIV is a strong effect modifier. We used the WHO 2013 definition [41], classifying HIV as positive, negative or unknown status (when the patient's HIV status had been determined after notification, HIV status is routinely reclassified in the database).

\section{Data sources}

The SPS-TB Program has had a specific strategy to improve its surveillance system since 1993. In this project we used the dedicated electronic system "TBweb" [44]. Since its inception, the SPS-TB Program has invested in the quality of data entry and maintenance of the consistency and validity of data. For instance, there is continuous audit and feedback, promotion of campaigns and rewarding of units for good data quality. We included data from 1 January 2009 to 31 December 2013 (dates of notification). The data were extracted on 31 October 2014.

\section{Plan of analysis \\ Sample size}

SPS has 18,000-20,000 TB cases per year, totalling around $90,000-100,000$ cases in our cohort [32]. Based on the TB Program reports, the estimated prevalence of homelessness among cases of tuberculosis is $2.5 \%$ [32]. With $90 \%$ power, type I error $5 \%$ and $20 \%$ unsuccessful outcome of treatment among those not homeless, our required sample size to evaluate the effect of homelessness was 3835 patients assuming $35 \%$ or more poor treatment outcomes among the homeless. Sample size was calculated in Epi Info 7 (CDC-USA), using Fleiss with continuity correction [45].

\section{Descriptive analysis}

We described the patients' general characteristics, showing the prevalence distribution of each variable. Categorical variables are shown as percentages and compared using the Fisher's exact test or a $\chi^{2}$ test. For the exposure and primary outcome, we calculated their point-estimate measure and its $95 \%$ confidence interval (CI) using the exact method.

\section{Univariate and adjusted analysis}

We used logistic regression models to evaluate the effect of homelessness on treatment outcome. Our main analysis was based on complete case analysis and we ran a sensitivity analysis using multiple imputation to deal with missing data.

We fitted univariate logistic regression models for the exposure and each potential confounding factor. To obtain an adjusted estimate of the association between homelessness and PTB treatment, we fitted a multivariate logistic regression. To build the final model, we included all a priori selected potential confounders. We also ran an additional final model to explore the interaction between homelessness and HIV status. 
To conduct the multiple imputation, we first investigated the patterns of missing variables. We assumed the missing values to be missing at random (MAR) and explored whether they were conditioned on observed variables, suggesting a MAR mechanism [46].

We used a multivariate normal model and imputed the variables age, country of birth, race, education, place of diagnosis, chest $\mathrm{x}$-ray, microbiologic status and DOT. We followed the recommended steps to build the imputed model [46], including all variables used in the final model as regular variables and the outcome. We also used auxiliary variables (year of notification, administrative region) and passive terms (HIV interaction). We generated five imputed datasets and, after the imputing process, we converted the continuous variables to categorical variables by "adaptive rounding" [47]. We combined the results using Rubin's rule [48] and checked the convergence of the simulations by analysing the worst linear function (WLF) over successive iterations.

For all logistic regression models, we tested the hypothesis using likelihood ratio tests. For $95 \% \mathrm{CI}$, we used the quadratic approximation of the log likelihood (Wald intervals). For the logistic regression models fitted in the multiple imputed data, we used Wald tests. In the fully-adjusted models, multicollinearity was assessed by the amount of variation on the standard errors of parameters on the logarithmic scale, comparing the model with and without the variable of interest.
We estimated the population attributable fraction (PAF) of vulnerable conditions from the final multivariate model by using the standard formula:

$$
P A F=p^{\prime} \frac{\theta-1}{\theta}
$$

where $p^{\prime}$ was the proportion of cases exposed and $\theta$ was the OR from the multivariable model.

All analyses were conducted in STATA 13.1 (StataCorp-Texas). Further definitions and additional methodology are given in the online supplementary material (Additional file 1: eTable 1) [2, 41].

\section{Results}

The flowchart is shown in Fig. 1. Of 93,259 adult TB patients, we excluded $16 \%(15,003)$ because of previous treatment, $1 \%$ (886) because they were diagnosed at necropsy and $0.5 \%$ (459) because they were still on treatment. From the remaining 76,911 patients, we excluded $19.6 \%(15,094)$ because they had EPTB. Therefore, we analysed 61,817 newly diagnosed patients with PTB only.

\section{General characteristics of the homeless}

The prevalence of homelessness among PTB patients was $2.8 \%$ (95 \% CI 2.7-2.9 \%; 1726/61,817). The majority of cases who were homeless were observed in big cities: four

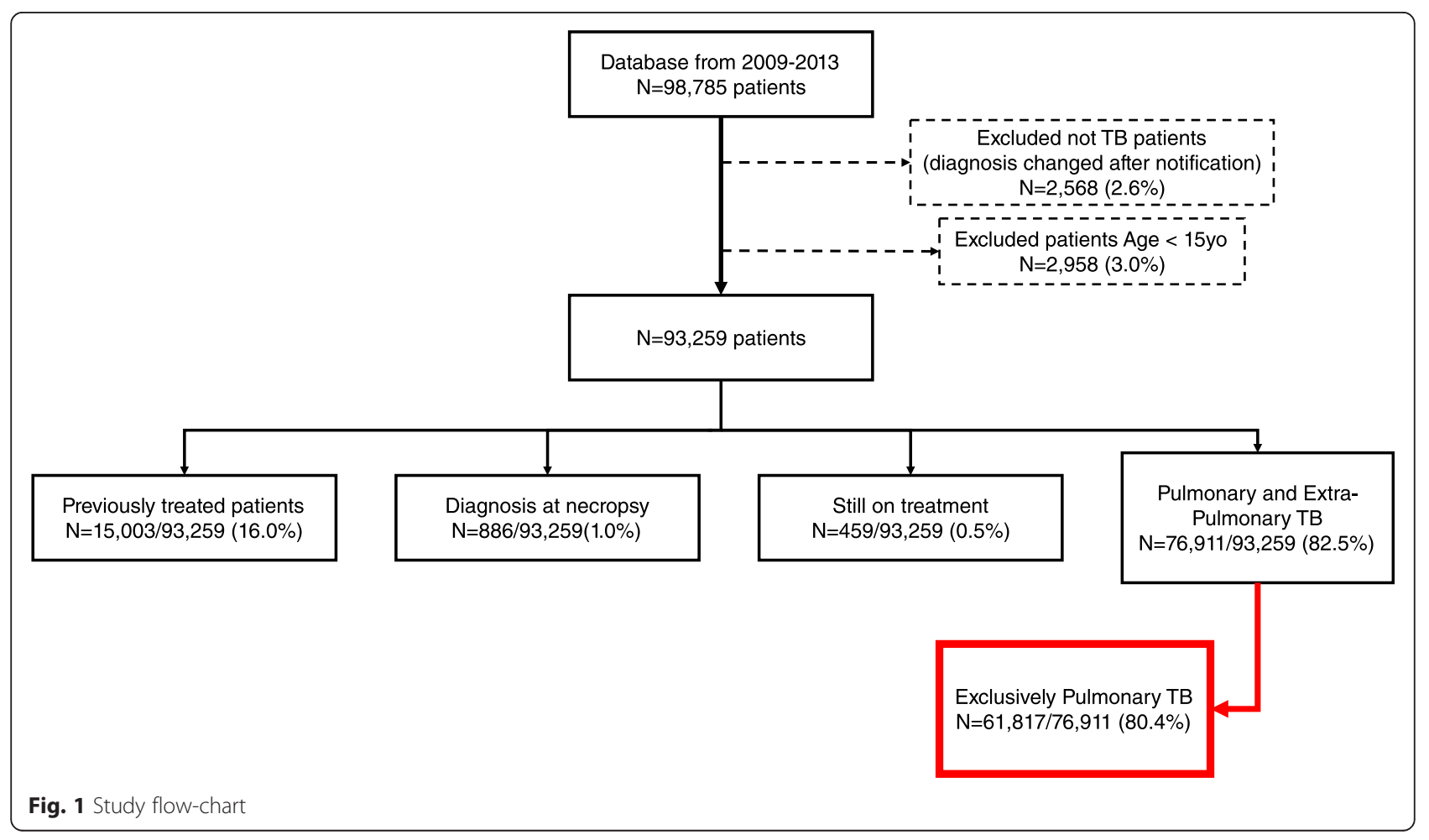


cities with more than 750,000 inhabitants had $5.5 \%$ $(1305 / 23,558)$ prevalence of homelessness and comprised $76 \%(1305 / 1726)$ of all cases who were homeless.

General characteristics are reported in Table 1. Homeless patients were more frequently middle-aged males (ratio male/female of 6.75), black/brown skin colour, and less educated $(\mathrm{P}<0.001$, for all). The prevalence of alcohol and drug use was three times more frequent in homeless patients (43.2\% vs. $14.4 \%, 30.2 \%$ vs. $9.4 \%, \mathrm{P}<0.001$, respectively). There was a marked intersection between homelessness and alcohol and/or drug use (Fig. 2). Diabetes mellitus was present in $6.3 \%$ of patients, while mental disorders and "other immunosuppression" had a very low prevalence $(1.9 \%$ and $0.7 \%$, respectively). The prevalence of all such comorbidities was lower in the homeless patients, except for mental disorders. Overall, HIV testing was high ( 85\%), but homeless patients were less frequently tested. The prevalence of HIV positivity was twice as high among homeless cases (17.3\% vs. $8.5 \%$, $\mathrm{P}<0.001)$.

Almost two thirds of patients were diagnosed outside hospitals. However, homeless individuals were frequently diagnosed at emergency services $(34.7 \%)(\mathrm{P}<0.001)$. In terms of chest $\mathrm{x}$-rays at diagnosis, $76.4 \%$ had positive findings for PTB. Microbiologic confirmation diagnosis occurred more frequently among the homeless (91.6\% vs. $84.8 \%, \mathrm{P}<0.001$ ). The majority of patients (approximately $80 \%)$ were treated with the four drugs scheme (RHZE). DOT was offered to $73.5 \%$ of patients overall and to $69.6 \%$ of homeless patients $(\mathrm{P}<0.001)$.

\section{Homelessness and treatment outcomes}

The treatment outcomes are shown in Table 2. The percentage of treatment success among all cases was high: 81.4 \% (95 \% CI, 81.1-81.7). Among homeless patients the percentage of unsuccessful outcome of treatment was $57.3 \%$ (OR 6.32, 95 \% CI 5.73-6.97, P < 0.001). Loss to follow-up $(39.0 \%)$ and death $(10.5 \%)$ were the main problems.

After full adjustment, our model in the complete case analysis evaluated 36,604 (59 \%) patients, as shown in Table 3. Homelessness remained strongly associated with poor outcomes (aOR 4.96, 95 \% CI 4.27-5.76, $\mathrm{P}<0.001$ ). The influence of age in the unsuccessful results of treatment was non-linear, with older patients being associated with higher odds of poor outcomes $(\mathrm{P}<0.001)$. Being male, non-white and non-Brazilian were associated with worse outcomes. Higher level of education was non-linearly associated with better outcomes, with strong protective impact after eight years of education. Alcohol and drug use had a marked effect on unsuccessful outcomes of treatment (aOR 1.33, 95 \% CI 1.23-1.44, P < 0.001 and aOR 2.06, $95 \%$ CI 1.89-2.24, $\mathrm{P}<0.001$, respectively). After adjustment, diabetes mellitus, mental disorders and other immunosuppression showed no evidence of association with unsuccessful outcomes of treatment. Patients diagnosed at emergency services or when hospitalized had worse outcomes (aOR 1.54, $95 \%$ CI 1.44-1.65 and aOR $1.89,95 \%$ CI 1.73-2.06, P < 0.001, respectively). Analysis of chest x-ray pattern at diagnosis showed that patients with cavitation had better outcomes than patients who did not have a chest $\mathrm{x}$-ray. Patients with confirmed microbiological diagnosis had an aOR of 0.92 (95 \% CI 0.85-1.00, P = 0.048) for unsuccessful outcomes of treatment. Finally, patients who received the recommended drugs (triple until 2009 or quadruple after 2010) and those who received DOT had better outcomes. There was no evidence of multicollinearity in the final model.

\section{Sensitivity analysis in multiple imputed data}

We observed missing values for eight variables: age $(<0.1 \%)$, DOT $(0.9 \%)$, place of diagnosis (1.5\%), chest $\mathrm{x}$-ray (4.6\%), microbiologic status (5.2\%), race (15.5\%), country of birth (16.2\%) and education level (19.5\%). The multiple imputation process had good convergence as evaluated by the WLF.

Homelessness remained strongly associated with unsuccessful outcome of treatment (aOR 4.81, 95 \% CI 4.33$5.35, \mathrm{P}<0.001)$ after full adjustment in multiple imputed analyses (Additional file 1: eTable 2). There were almost no changes in the point-estimate values for aORs compared with the complete case analysis. However, some covariates presented strong evidence of association not observed in the complete case analysis, such as diabetes mellitus, other immunosuppression and microbiologic diagnosis (Additional file 1: eTable 2).

\section{Interaction with HIV status}

For the evaluation of the interaction effect on the fully adjusted model, we used the multiple imputed datasets to increase power. HIV status had a marked effect modification for homelessness $\left(P_{\text {interaction }}<0.001\right.$ for interaction), changing its association among HIV positive patients (aOR 2.45, 95 \% CI 1.90-3.16) (Fig. 3, Additional file 1: eTable 3).

\section{Population attributable fraction-PAF}

From the final model of the complete case analysis, we estimated the PAF for homelessness. Because homelessness was strongly associated with alcohol and drug use (Table 4), we estimated a joint PAF for these three factors. When combined, their PAF totalled nearly $20.0 \%$.

\section{Discussion}

Our study showed that $2.8 \%$ (95 \% CI 2.7-2.9\%) of newly diagnosed PTB patients in SPS during 2009-2013 were homeless. Homelessness had a marked association with unsuccessful outcome of treatment (aOR 4.96, 
Table 1 Comparison of general characteristics of newly diagnosed pulmonary TB patients who were homeless and those who were not

\begin{tabular}{|c|c|c|c|c|c|}
\hline & Values & $\begin{array}{l}\text { Overall } \\
(n=61817)\end{array}$ & $\begin{array}{l}\text { Not Homelessness } \\
(n=60091)\end{array}$ & $\begin{array}{l}\text { Homelessness } \\
(\mathrm{n}=1726)\end{array}$ & $P$ value \\
\hline \multirow[t]{9}{*}{ Age, years } & $15-25$ & 12734 (20.6 \%) & 12616 (21.0\%) & 118 (6.9 \%) & $<0.001$ \\
\hline & $25.1-35$ & 16733 (27.1\%) & 16301 (27.2 \%) & 432 (25.1 \%) & \\
\hline & $35.1-45$ & 11951 (19.4 \%) & 11417 (19.0\%) & 534 (31.0 \%) & \\
\hline & $45.1-55$ & 10215 (16.5 \%) & 9794 (16.3 \%) & 421 (24.5 \%) & \\
\hline & $55.1-65$ & 6010 (9.7\%) & 5833 (9.7 \%) & 177 (10.3 \%) & \\
\hline & $65.1-75$ & 2719 (4.4 \%) & $2683(4.5 \%)$ & $36(2.1 \%)$ & \\
\hline & $75.1-85$ & 1170 (1.9\%) & $1168(2.0 \%)$ & 2 (0.1\%) & \\
\hline & $85.1-105$ & $230(0.4 \%)$ & $229(0.4 \%)$ & 1 (0.1\%) & \\
\hline & Missing & $55(0.1 \%)$ & $50(0.1 \%)$ & 5 (0.3\%) & \\
\hline \multirow[t]{2}{*}{ Gender } & Female & 17245 (27.9 \%) & 17023 (28.3 \%) & $222(12.9 \%)$ & $<0.001$ \\
\hline & Male & 44572 (72.1 \%) & 43068 (71.7 \%) & 1504 (87.1%) & \\
\hline \multirow[t]{3}{*}{ Country of birth } & Brazil & 50410 (97.2 \%) & 49151 (97.2 \%) & 1259 (98.7 \%) & 0.002 \\
\hline & Not-Brazil & $1423(2.8 \%)$ & 1406 (2.8 \%) & 17 (1.3 \%) & \\
\hline & Missing & 9984 (16.2 \%) & 9534 (15.9 \%) & 450 (26.1 \%) & \\
\hline \multirow[t]{6}{*}{ Race } & White & 26931 (51.6 \%) & 26396 (51.9 \%) & 535 (38.4 \%) & $<0.001$ \\
\hline & Black & 6106 (11.7 \%) & 5819 (11.5 \%) & 287 (20.6 \%) & \\
\hline & Mixed/Brown & 18180 (34.8 \%) & 17615 (34.7 \%) & 565 (40.5 \%) & \\
\hline & Asian & $556(1.1 \%)$ & 549 (1.1\%) & 7 (0.5 \%) & \\
\hline & Indigenous & 444 (0.9 \%) & 443 (0.9 \%) & 1 (0.1\%) & \\
\hline & Missing & 9600 (15.5 \%) & 9269 (15.4 \%) & 331 (19.2 \%) & \\
\hline \multirow[t]{7}{*}{ Education } & Illiterate & 1955 (3.9 \%) & 1886 (3.9 \%) & 69 (5.9\%) & $<0.001$ \\
\hline & 1-3 years & 6122 (12.3 \%) & 5920 (12.2 \%) & 202 (17.3 \%) & \\
\hline & 4-7 years & 19178 (38.5 \%) & 18651 (38.4\%) & $527(45.0 \%)$ & \\
\hline & 8-11 years & 18155 (36.5 \%) & 17821 (36.7\%) & 334 (28.5 \%) & \\
\hline & $12-14$ years & 3034 (6.1 \%) & 3005 (6.2\%) & $29(2.5 \%)$ & \\
\hline & $>=15$ years & 1327 (2.7 \%) & 1317 (2.7 \%) & 10 (0.9 \%) & \\
\hline & Missing & 12046 (19.5 \%) & 11491 (19.1\%) & 555 (32.2 \%) & \\
\hline \multirow[t]{2}{*}{ Alcohol } & No & $52430(84.8 \%)$ & $51450(85.6 \%)$ & $980(56.8 \%)$ & $<0.001$ \\
\hline & Yes & 9387 (15.2 \%) & 8641 (14.4\%) & $746(43.2 \%)$ & \\
\hline \multirow[t]{2}{*}{ Diabetes mellitus } & No & 57955 (93.7 \%) & $56279(93.6 \%)$ & 1676 (97.1%) & $<0.001$ \\
\hline & Yes & $3862(6.3 \%)$ & $3812(6.4 \%)$ & $50(2.9 \%)$ & \\
\hline \multirow[t]{2}{*}{ Drug users } & No & $55639(90.0 \%)$ & $54434(90.6 \%)$ & 1205 (69.8 \%) & $<0.001$ \\
\hline & Yes & $6178(10.0 \%)$ & $5657(9.4 \%)$ & $521(30.2 \%)$ & \\
\hline \multirow[t]{2}{*}{ Mental disorder } & No & $60673(98.1 \%)$ & $58999(98.2 \%)$ & 1674 (97.0 \%) & $<0.001$ \\
\hline & Yes & $1144(1.9 \%)$ & $1092(1.8 \%)$ & $52(3.0 \%)$ & \\
\hline \multirow[t]{2}{*}{ Other immunosuppression } & No & 61379 (99.3 \%) & $59656(99.3 \%)$ & 1723 (99.8 \%) & 0.007 \\
\hline & Yes & $438(0.7 \%)$ & 435 (0.7 \%) & $3(0.2 \%)$ & \\
\hline \multirow[t]{3}{*}{ HIV status } & Negative & 47389 (76.7 \%) & 46399 (77.2 \%) & $990(57.3 \%)$ & $<0.001$ \\
\hline & Positive & $5391(8.7 \%)$ & $5093(8.5 \%)$ & $298(17.3 \%)$ & \\
\hline & Unknown & 9037 (14.6 \%) & 8599 (14.3\%) & $438(25.4 \%)$ & \\
\hline \multirow[t]{2}{*}{ Place of diagnosis } & PHC/Ambulatory & 40110 (65.9\%) & $39199(66.3 \%)$ & $911(53.2 \%)$ & $<0.001$ \\
\hline & Emergency service & 13255 (21.8 \%) & $12661(21.4 \%)$ & $594(34.7 \%)$ & \\
\hline
\end{tabular}


Table 1 Comparison of general characteristics of newly diagnosed pulmonary TB patients who were homeless and those who were not (Continued)

\begin{tabular}{|c|c|c|c|c|c|}
\hline & Hospital & 7499 (12.3 \%) & 7293 (12.3 \%) & $206(12.1 \%)$ & \\
\hline & Missing & $953(1.5 \%)$ & $938(1.6 \%)$ & $15(0.9 \%)$ & \\
\hline \multirow[t]{6}{*}{ Chest x-ray } & Not done & 9409 (15.2 \%) & 9075 (15.8 \%) & $334(20.9 \%)$ & $<0.001$ \\
\hline & Normal & 2107 (3.4 \%) & 2049 (3.6 \%) & 58 (3.6 \%) & \\
\hline & Additional pathology & $245(0.4 \%)$ & $237(0.4 \%)$ & $8(0.5 \%)$ & \\
\hline & Suggestive of TB & $35221(57.0 \%)$ & 34295 (59.8 \%) & $926(58.0 \%)$ & \\
\hline & Cavitation & 11995 (19.4 \%) & 11725 (20.4 \%) & $270(16.9 \%)$ & \\
\hline & Missing & 2840 (4.6 \%) & 2710 (4.5\%) & $130(7.5 \%)$ & \\
\hline \multirow[t]{3}{*}{ Microbiological status } & Negative & 8787 (15.0 \%) & 8647 (15.2 \%) & $140(8.4 \%)$ & $<0.001$ \\
\hline & Positive & 49844 (85.0 \%) & 48318 (84.8 \%) & 1526 (91.6 \%) & \\
\hline & Missing & 3186 (5.2 \%) & 3126 (5.2 \%) & 60 (3.5 \%) & \\
\hline \multirow[t]{3}{*}{ Initial drug scheme } & Other & 1361 (2.2 \%) & 1232 (2.1 \%) & $129(7.5 \%)$ & $<0.001$ \\
\hline & $\mathrm{RHZ}$ & 11356 (18.4 \%) & 11101 (18.5 \%) & $255(14.7 \%)$ & \\
\hline & RHZE & 49100 (79.4 \%) & 47758 (79.5 \%) & 1342 (77.8 \%) & \\
\hline \multirow[t]{3}{*}{ Directly observed treatment-DOT } & No & 16219 (26.5 \%) & 15724 (26.4 \%) & 495 (30.4 \%) & $<0.001$ \\
\hline & Yes & $45050(73.5 \%)$ & 43918 (73.6 \%) & 1132 (69.6 \%) & \\
\hline & Missing & $548(0.9 \%)$ & $449(0.8 \%)$ & $99(5.7 \%)$ & \\
\hline
\end{tabular}

PHC primary health clinics, $R$ rifampicin, $H$ isoniazid, $Z$ pyrazinamide, $E$ ethambutol

$95 \%$ CI 4.27-5.76, P < 0.001) after adjusting for several confounding factors; we found similar results in the multiple imputed data analysis. Losses to follow-up and deaths were the main poor outcomes for the homeless. Homelessness, alcohol use and drug use had a joint PAF of $\sim 20 \%$. Interestingly, HIV status exerted an effect modification on the association between homelessness and unsuccessful outcome of treatment.

Unsuccessful outcome of treatment among homeless patients was very high (57.3\%) in our analysis, comparable to a cohort study in London in 2003 [26]. The association of homelessness with poor outcomes has

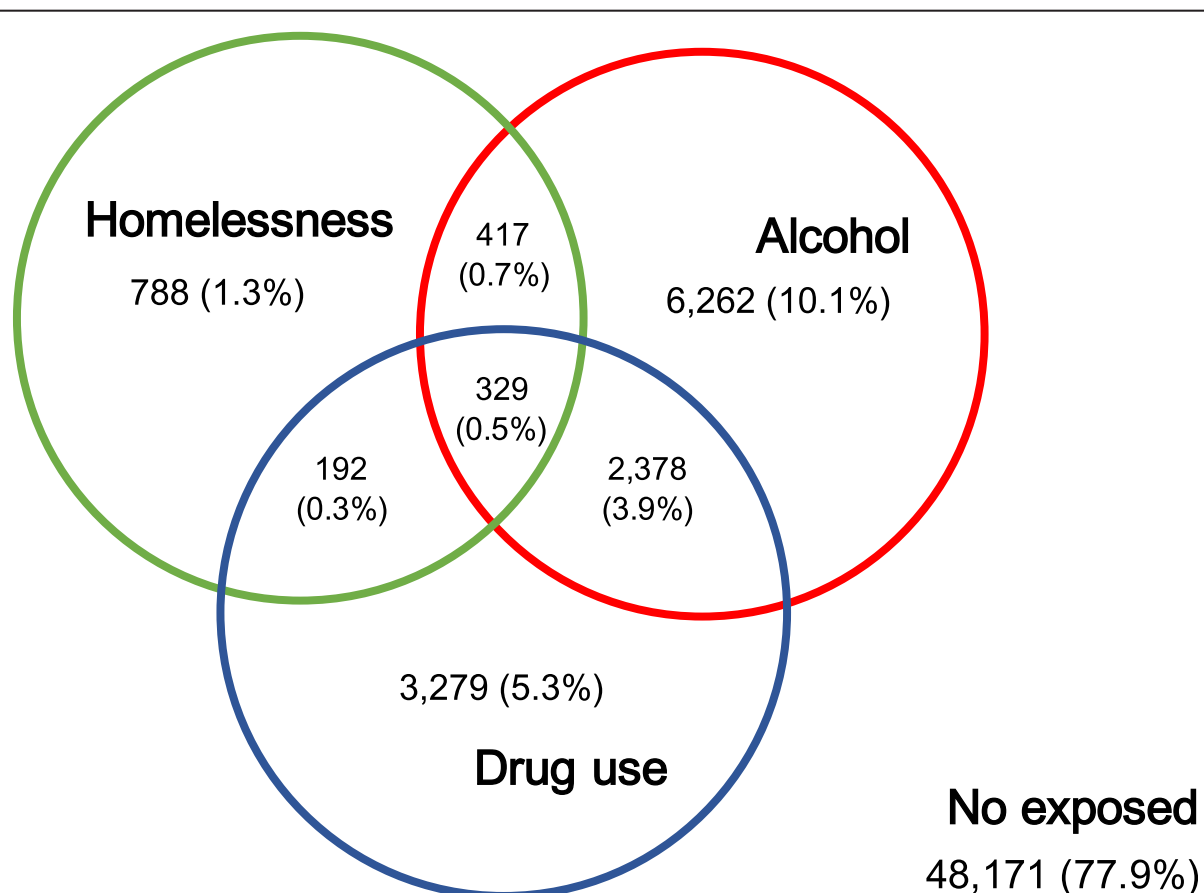

Fig. 2 Intersection between homelessness, alcohol use and drug use 
Table 2 Treatment outcomes among 61,817 newly diagnosed PTB and their distribution among patients who were homeless and those who were not

\begin{tabular}{llcc}
\hline Treatment outcomes $^{\mathrm{a}}$ & $\begin{array}{l}\text { Overall } \\
(\mathrm{n}=61817)\end{array}$ & $\begin{array}{l}\text { Not Homelessness } \\
(\mathrm{n}=60091)\end{array}$ & $\begin{array}{l}\text { Homelessness } \\
(\mathrm{n}=1726)\end{array}$ \\
\hline & $50302(81.4 \%)$ & $49565(82.5 \%)$ & $737(42.7 \%)$ \\
Treatment success & $374(0.6 \%)$ & $367(0.6 \%)$ & $7(0.4 \%)$ \\
Treatment failure & $3800(6.2 \%)$ & $3619(6.0 \%)$ & $181(10.5 \%)$ \\
Death & $6307(10.2 \%)$ & $5633(9.4 \%)$ & $674(39.0 \%)$ \\
Loss to follow-up & $1034(1.7 \%)$ & $907(1.5 \%)$ & $127(7.4 \%)$ \\
Not evaluated & &
\end{tabular}

${ }^{\text {a }}$ Treatment outcome definitions are in the online material

been strong in developed countries [42, 49-52], achieving an aOR of 9.91 (95\% CI 4.38-22.38) in an Italian cohort with $3.8 \%(60 / 1564)$ prevalence of homelessness [53]. In contrast, a Spanish cohort showed no association between homelessness (prevalence $2.1 \%$ ) and poor outcomes after adjustment for predominating age, alcohol use, drug use, immigration and HIV status [54]. In terms of low- and middle-income countries, a study in Nicaragua showed that homelessness was associated with loss to follow-up $(\mathrm{n}=502$, aOR 3.00, $95 \% \mathrm{CI}$ 1.44-6.23) [55]. In a small cross-sectional study from Colombia which analysed deaths in TB patients, homelessness was present in $22 \%(12 / 55)$ of cases, the majority being diagnosed at hospital, suggesting late diagnosis [56].

Two overlapped population-based cohorts from the USA (1994-2003 and 1994-2010), similar in approach to our study, reported a prevalence of homelessness around $6 \%$ among TB cases [24, 25]. Homeless cases had characteristics comparable to our cohort: young adult males, high prevalence of alcohol and drug abuse and high prevalence of HIV positivity. In the 1994-2003 cohort, treatment success was $77 \%$ for homelessness vs. $84 \%$ for non-homelessness. DOT coverage was $86 \%$ and homeless patients who received DOT were more likely to complete treatment [25]. In the 1994-2010 cohort, homelessness had twice the odds for unsuccessful outcome of treatment [24]. Both USA cohorts included PTB, EPTB and re-treatment cases. Although there were similarities with our population, homelessness was associated with unsuccessful outcome of treatment to a much lower degree in the USA. Improved social support $[24,25,27,57]$ and campaigns to improve housing during treatment [58] could explain these differences and show that the challenge of successful treatment of tuberculosis among the homeless can be met.

Our final model was generally consistent with the literature, highlighting the impact of important features on TB treatment outcomes. Diabetes mellitus was associated with better outcomes in the multiple imputed analysis, although in the literature it has been associated with death and treatment failure [20]. We believe that putting together all the "undesired outcomes" as unsuccessful outcome of treatment, we were unable to observe this association, as diabetes would decrease cure and increase mortality but not increase loss to follow-up. In fact, diabetes patients are likely to be followed up for medical treatment. The influence of microbiological confirmation $[12,15,19]$ and chest x-ray [12] are controversial, with studies showing different associations for TB outcomes. Interestingly, we found that the effect of homelessness was less pronounced among HIV positive patients. We hypothesized that for these patients, PTB treatment was prioritized, leading to better management and follow-up by the TB and HIV-AIDS program than for HIV negative or unknown groups.

This study analysed a large dataset that covers all of SPS (41 million inhabitants). We followed our a priori plan of analysis, using multiple imputation to deal with missing data. We estimated the PAF for vulnerable conditions, a cornerstone of public health decisions. Few studies have addressed this issue, although PAF is fundamental to addressing the "social face" of TB [2, 3, 23]. Assuming a causal association between lower treatment success and homelessness, alcohol use and drug use, we estimated around $20 \%$ of unsuccessful outcome of treatment in our population would be prevented if we could eliminate these exposures, or the increased risk associated with them.

The study has some limitations. First, the ascertainment of homelessness is unlikely to have false-positives. However, we cannot be confident that no patients pretended not to be homeless for reasons of stigmatisation. Therefore, we could have underestimated the prevalence and the impact of homelessness in our study. Second, we analysed only newly diagnosed PTB, which strengthened our internal validity but could have decreased our perception of the TB burden due to homelessness. Indeed, it is likely that homelessness prevalence is higher among relapses, re-treatments and other clinical forms of TB. Our aim was to provide data to plan interventions; therefore, we restricted our analysis to pulmonary cases, which are responsible for most transmission and 
Table 3 Fully adjusted estimates for the association between homelessness and unsuccessful outcome of treatment of newly diagnosed PTB by logistic regression model ( $n=36,604$, complete case analysis)

\begin{tabular}{|c|c|c|c|c|}
\hline & & Values & Adjusted OR (95\% Cl) & $P$ value \\
\hline \multirow[t]{2}{*}{ Exposure } & Homelessness & No & Reference & $<0.001$ \\
\hline & & Yes & $4.96(4.27-5.76)$ & \\
\hline \multirow{39}{*}{ Adjusted for } & Age, years & $15-25$ & Reference & $<0.001$ \\
\hline & & $25.1-35$ & $1.01(0.93-1.10)$ & $P_{\text {dep }}<0.001$ \\
\hline & & $35.1-45$ & $0.93(0.85-1.02)$ & \\
\hline & & $45.1-55$ & $0.84(0.76-0.93)$ & \\
\hline & & $55.1-65$ & $0.94(0.83-1.06)$ & \\
\hline & & $65.1-75$ & $1.08(0.92-1.27)$ & \\
\hline & & $75.1-85$ & $1.92(1.56-2.36)$ & \\
\hline & & $85.1-105$ & $2.47(1.62-3.76)$ & \\
\hline & Gender & Female & Reference & $<0.001$ \\
\hline & & Male & $1.32(1.23-1.41)$ & \\
\hline & Country of birth & Brazil & Reference & $<0.001$ \\
\hline & & Not-Brazil & $2.09(1.74-2.51)$ & \\
\hline & Race & White & Reference & 0.001 \\
\hline & & Black & $1.16(1.06-1.28)$ & \\
\hline & & Mixed/Brown & $1.08(1.01-1.15)$ & \\
\hline & & Asian & $0.82(0.59-1.13)$ & \\
\hline & & Indigenous & $1.48(1.10-1.99)$ & \\
\hline & Education & Illiterate & Reference & $<0.001$ \\
\hline & & 1-3 years & $1.04(0.88-1.23)$ & $P_{\text {dep }}<0.001$ \\
\hline & & 4-7 years & $1.07(0.92-1.25)$ & \\
\hline & & 8-11 years & $0.84(0.72-0.99)$ & \\
\hline & & $12-14$ years & $0.57(0.46-0.70)$ & \\
\hline & & $>=15$ years & $0.62(0.48-0.81)$ & \\
\hline & Alcohol & No & Reference & $<0.001$ \\
\hline & & Yes & $1.33(1.23-1.44)$ & \\
\hline & Diabetes mellitus & No & Reference & 0.173 \\
\hline & & Yes & $0.92(0.81-1.04)$ & \\
\hline & Drug users & No & Reference & $<0.001$ \\
\hline & & Yes & $2.06(1.89-2.24)$ & \\
\hline & Mental disorder & No & Reference & 0.441 \\
\hline & & Yes & $1.10(0.87-1.38)$ & \\
\hline & Other immunosuppression & No & Reference & 0.144 \\
\hline & & Yes & $1.29(0.92-1.79)$ & \\
\hline & Place of diagnosis & PHC/Ambulatory & Reference & $<0.001$ \\
\hline & & Emergency service & $1.54(1.44-1.65)$ & \\
\hline & & Hospital & $1.89(1.73-2.06)$ & \\
\hline & Chest x-ray & Not done & Reference & $<0.001$ \\
\hline & & Normal & $0.96(0.80-1.15)$ & \\
\hline & & Additional pathology & $1.07(0.64-1.79)$ & \\
\hline
\end{tabular}


Table 3 Fully adjusted estimates for the association between homelessness and unsuccessful outcome of treatment of newly diagnosed PTB by logistic regression model ( $n=36,604$, complete case analysis) (Continued)

\begin{tabular}{|c|c|c|c|}
\hline & Suggestive of TB & $1.04(0.95-1.14)$ & \\
\hline & Cavitation & $0.86(0.78-0.96)$ & \\
\hline \multirow[t]{2}{*}{ Microbiologic status } & Negative & Reference & \multirow[t]{2}{*}{0.048} \\
\hline & Positive & $0.92(0.85-1.00)$ & \\
\hline \multirow[t]{3}{*}{ Initial drug scheme } & Other & Reference & \multirow[t]{3}{*}{$<0.001$} \\
\hline & $\mathrm{RHZ}$ & $0.73(0.59-0.91)$ & \\
\hline & RHZE & $0.65(0.53-0.80)$ & \\
\hline \multirow[t]{2}{*}{ Directly observed treatment-DOT } & No & Reference & \multirow[t]{2}{*}{$<0.001$} \\
\hline & Yes & $0.45(0.42-0.48)$ & \\
\hline
\end{tabular}

$O R$ odds ratio, $C l$ confidence interval, $P_{\text {dep }}$ test for departure from linearity, $P H C$ primary health clinics, $R$ rifampicin, $H$ isoniazid, $Z$ pyrazinamide and $E$ ethambutol

the main burden of TB. Third, we applied the WHO definition for HIV status, which could be an issue because "HIV unknown" would include both positive and negative patients [17]. However, this was less important because of the high HIV testing in our population. The factors beyond not testing for HIV in PTB patients should be further explored. Fourth, by grouping the negative outcomes as unsuccessful outcome of treatment, we were not able to differentiate the effect on specific negative outcomes. The pragmatic approach of our analysis using routine data to inform stakeholders justifies our analysis; however, we believe that TB outcomes definitions and means of analysing them should be improved.

To improve TB health care for vulnerable groups is a difficult task which requires multifaceted interventions [22, 31, 59], involving governmental and community actions. There are several barriers, from finance to human support [59]. Indeed, adherence to TB treatment is strongly influenced by disease awareness and stigmatisation [30].

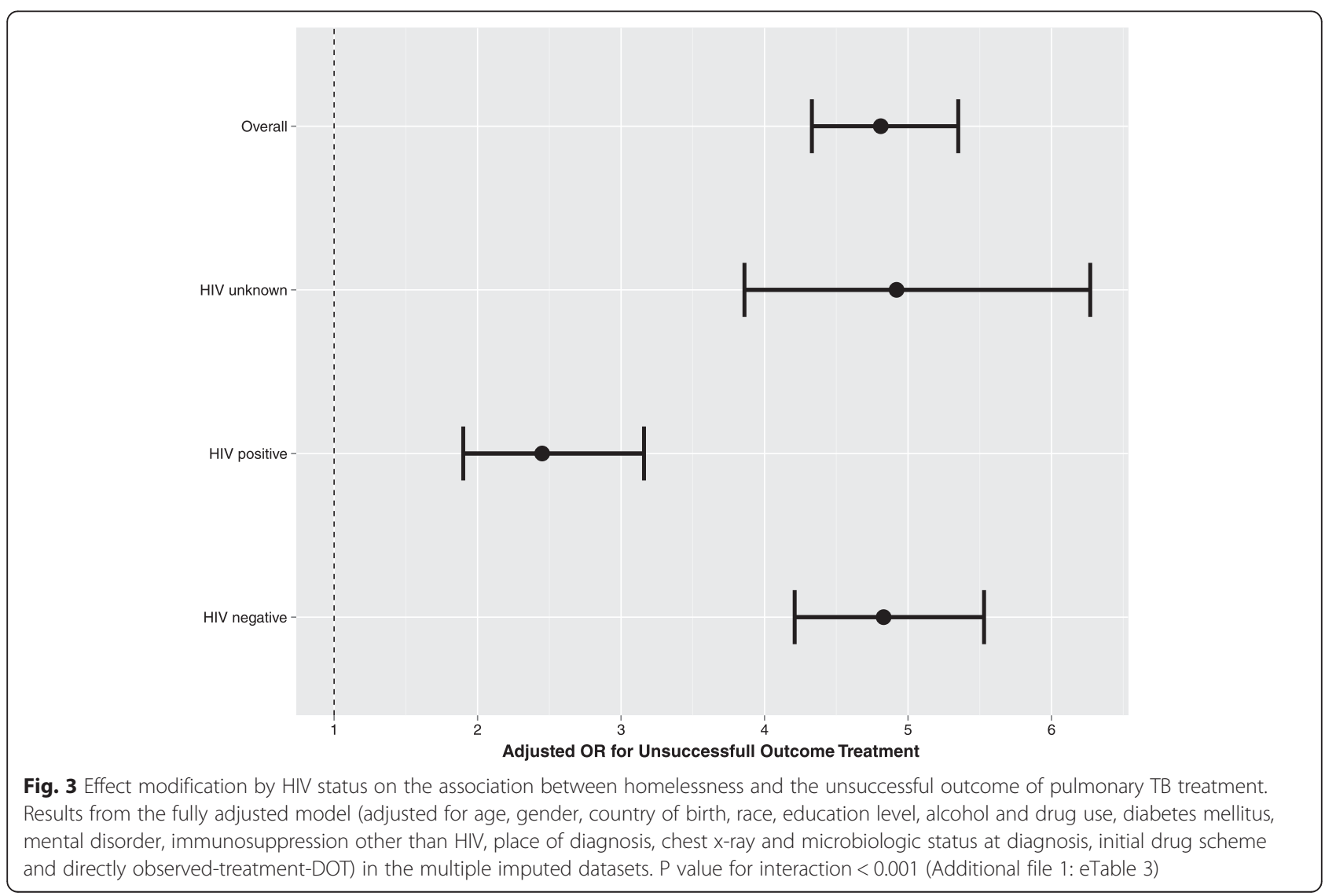


Table 4 Joint population attributable fraction for impact of homelessness, alcohol and drug use on the unsuccessful outcome of treatment of newly diagnosed PTB cases ( $n=61,817$ cases)

\begin{tabular}{lllllll}
\hline Homelessness & Alcohol & Drug users & Number $(\%)$ & $\begin{array}{l}\text { Odds ratio to unsuccessful } \\
\text { outcome of treatment }\end{array}$ & $\begin{array}{l}\text { Proportion among unsuccessful } \\
\text { outcome of treatment - } \%\end{array}$ & $\begin{array}{l}\text { PAF for unsuccessful } \\
\text { outcome of treatment - } \%\end{array}$ \\
\hline No & No & No & $48171(77.9 \%)$ & Reference & $65.0 \%$ & $4.4 \%$ \\
No & No & Yes & $3279(5.3 \%)$ & 2.33 & $7.7 \%$ & $12.3 \%$ \\
No & Yes & No & $6263(10.1 \%)$ & 1.52 & $6.4 \%$ & $3.2 \%$ \\
No & Yes & Yes & $2378(3.9 \%)$ & 2.56 & $3.9 \%$ & $3.9 \%$ \\
Yes & No & No & $788(1.3 \%)$ & 6.25 & $1.2 \%$ & $1.3 \%$ \\
Yes & No & Yes & $192(0.3 \%)$ & 16.7 & $1.8 \%$ & $1.1 \%$ \\
Yes & Yes & No & $417(0.7 \%)$ & 5.56 & $1.7 \%$ & $1.5 \%$ \\
Yes & Yes & Yes & $329(0.5 \%)$ & 9.09 & $1.5 \%$ & \\
\hline
\end{tabular}

PTB pulmonary tuberculosis, PAF population attributable fraction

Additionally, TB treatment is associated with high direct/ indirect costs [6], as social support is needed to achieve compliance [4]. Some interventions have had promising results for LTBI treatment in homeless patients, in addition to nurse case management with educational programs and incentives [60] and monetary incentives alone [61, 62]. For PTB treatment, focus on DOT strategy together with incentives at each visit and bonuses after completion were associated with positive results in the USA [8, 27]. In Japan, the combination of DOT with social support was associated not only with better outcomes but also empowerment of homeless patients [63].

Brazil has a national universal health coverage system and TB treatment is fully provided for free by the TB Program. Important improvements in the program have been made, although a special focus on the homeless is needed. We observed a high proportion of homeless patients being diagnosed at hospitals. Together with other important factors for poor outcomes, we propose that homeless patients are more likely to have delayed diagnosis and worse access to health care [64]. Active case finding in the homeless population and at shelter admission could be an effective strategy to tackle delayed diagnosis [65]. Furthermore, we observed that the proportion of homeless patients who received DOT was lower than non-homeless patients, although we had expected the contrary. The implementation of a specific campaign for DOT among the homeless, additionally providing socio-economic support might be a feasible and effective strategy to achieve better treatment outcomes in this vulnerable group $[27,57]$. Structural and social transformations are necessary, improving not only $\mathrm{TB}$ treatment, but decreasing $\mathrm{TB}$ incidence in this population. Conditional cash transfer programs [66], food provision during treatment [40] and mobile health units for care of the homeless are promising in this setting [67].

Vulnerable conditions are so important for $\mathrm{TB}$ that guidelines and policy reports have launched specific documents for vulnerable groups $[29,30]$. It is important to discuss the ethical issues surrounding $\mathrm{TB}$, vulnerable groups and the implemented strategies [68].

\section{Conclusions}

In our study we reported the main features of PTB among the homeless and found evidence that homelessness plays an important role in the PTB burden in a middle-income country such as Brazil. We believe that specific local policies dedicated to this vulnerable group and $\mathrm{TB}$ are fundamental and should be further discussed and implemented.

\section{Ethical consideration}

We had official written permission from the Data Guardians, Health Department of SPS (21/05/2014) and Ethical Approval from the local Ethics Committee (03/09/2014, CAPPEsq-270/14) and from the LSHTM Ethics Committee (05/05/2015, Ref 9754).

\section{Additional file}

Additional file 1: eTables 1. Adapted from 2013 WHO Definitions and reporting framework for tuberculosis - 2013 revision (updated December 2014). eTable 2. Fully adjusted estimates for association between homelessness and the unsuccessful outcome of treatment of newly diagnosed PTB by logistic regression model in five multiple imputed datasets ( $n=61,817)$. eTable 3. Interaction of HIV status in the association between homelessness and the unsuccessful outcome of treatment of newly diagnosed PTB by fully-adjusted logistic regression model in 5 multiple imputed datasets ( $n=61,817)$. (DOCX $35 \mathrm{~kb}$ )

\footnotetext{
Abbreviations

DOT: Directly observed-treatment; EPTB: Extra-pulmonary tuberculosis; HDI: Human development index; LTBI: Latent tuberculosis infection; MAR: Missing at random; OR: Odds ratio; PAF: Population attributable fraction; PTB: Pulmonary tuberculosis; RHZE: Rifampicin + isoniazid + pyrazinamide + ethambutol; SPS: São Paulo State; TB: Tuberculosis; WHO: World Health Organization; WLF: Worst linear function.
}

Competing interests

The authors declare that they have no competing interests. 


\section{Authors' contributions}

OTR, CRRC, EAW and LCR conceived of the study. OTR and LCR designed the study. OTR and LCR did the data analysis. OTR, CRRC, EAW and LCR interpreted the results. OTR wrote the first draft of the manuscript. CRRC, EAW and LCR revised the manuscript with important intellectual contributions. All authors read and approved the final manuscript.

\section{Acknowledgments}

Funding: This work was supported by the Wellcome Trust [104006/Z/14/Z] All authors carried out this research independently of the funding body. The findings and conclusions in this manuscript reflect the opinions of the authors alone.

We are grateful to Drs Vera Maria Neder Galesi, Laedi Alves Rodrigues dos Santos and Sidney Bombarda, on behalf of the Division of the Control of Tuberculosis from the Centre of Epidemiology Surveillance-"Prof. Alexandre Vranjac" at the Health Department in São Paulo State, who was in charge of the TB Program in São Paulo State and management of the database.

\section{Data sharing policy}

This study uses data from a routine electronic TB database belonging to the Health Department of São Paulo State. We will therefore ultimately be governed in respect of data sharing by the data owners: any requests to share will be subject to their permission, and to the approval of the ethics committees overseeing the use of these data sources. We will consider requests for data sharing on an individual basis, with an overall aim of sharing the full data whenever possible if the request is motivated by scientific factors. Please contact the corresponding author.

\section{Author details}

${ }^{1}$ Pulmonary Division, Heart Institute (InCor), Medical School, University of São Paulo, Av. Dr. Arnaldo, 455, $2^{\circ}$ andar, sala 2144, Post-code 01246903 São Paulo, Brazil. 'London School of Hygiene \& Tropical Medicine (LSHTM), Keppel Street, Room G9a, Post-code WC1E 7HT London, UK. ${ }^{3}$ Department of Epidemiology, Faculty of Public Health, University of Sao Paulo, Av. Dr. Arnaldo, 715, Post-code 01246904 São Paulo, Brazil.

\section{Received: 1 December 2015 Accepted: 18 February 2016} Published online: 23 March 2016

\section{References}

1. Lawn SD, Zumla Al. Tuberculosis Lancet. 2011;378(9785):57-72.

2. World Health Organization-WHO. Global tuberculosis report 2015. 2015. http://apps.who.int/iris/bitstream/10665/191102/1/9789241565059_eng. pdf?ua=1\%5D. Acessed 20 Dec 2015.

3. Hargreaves JR, Boccia D, Evans CA, Adato M, Petticrew M, Porter JD. The social determinants of tuberculosis: from evidence to action. Am J Public Health. 2011:101(4):654-62.

4. Munro SA, Lewin SA, Smith HJ, Engel ME, Fretheim A, Volmink J. Patient adherence to tuberculosis treatment: a systematic review of qualitative research. PLOS Med. 2007;4(7):e238

5. Merle CS, Fielding K, Sow OB, Gninafon M, Lo MB, Mthiyane T, et al. A four-month gatifloxacin-containing regimen for treating tuberculosis. N Engl J Med. 2014;371(17):1588-98

6. Tanimura T, Jaramillo E, Weil D, Raviglione M, Lonnroth K. Financial burden for tuberculosis patients in low- and middle-income countries: a systematic review. Eur Respir J. 2014;43(6):1763-75.

7. Wingfield T, Boccia D, Tovar M, Gavino A, Zevallos K, Montoya R, et al. Defining catastrophic costs and comparing their importance for adverse tuberculosis outcome with multi-drug resistance: a prospective cohort study. Peru PLoS Med. 2014;11(7):e1001675.

8. Davidson $\mathrm{H}$, Schluger NW, Feldman PH, Valentine DP, Telzak EE, Laufer FN. The effects of increasing incentives on adherence to tuberculosis directly observed therapy. Int J Tuberc Lung Dis. 2000;4(9):860-5.

9. Albuquerque MF, Batista JAL, Ximenes RA, Carvalho MS, Diniz GT, Rodrigues LC. Risk factors associated with death in patients who initiate treatment for tuberculosis after two different follow-up periods. Rev Bras Epidemiol. 2009;12:513-22.

10. Anyama N, Bracebridge S, Black C, Niggebrugge A, Griffin SJ. What happens to people diagnosed with tuberculosis? A population-based cohort. Epidemiol Infect. 2007;135(7):1069-76
11. Ditah IC, Reacher M, Palmer C, Watson JM, Innes J, Kruijshaar ME, et al. Monitoring tuberculosis treatment outcome: analysis of national surveillance data from a clinical perspective. Thorax. 2008;63(5):440-6.

12. Waitt CJ, Squire SB. A systematic review of risk factors for death in adults during and after tuberculosis treatment. Int J Tuberc Lung Dis. 2011;15(7):871-85.

13. Kwon YS, Kim YH, Song JU, Jeon K, Song J, Ryu YJ, et al. Risk factors for death during pulmonary tuberculosis treatment in Korea: a multicenter retrospective cohort study. J Korean Med Sci. 2014;29(9):1226-31.

14. de Albuquerque MF, Ximenes RA, Lucena-Silva N, de Souza WV, Dantas AT, Dantas OM, et al. Factors associated with treatment failure, dropout, and death in a cohort of tuberculosis patients in Recife, Pernambuco State. Brazil Cad Saude Publica. 2007;23(7):1573-82.

15. Orofino Rde L, Brasil PE, Trajman A, Schmaltz CA, Dalcolmo M, Rolla VC Predictors of tuberculosis treatment outcomes. J Bras Pneumol. 2012;38(1): 88-97.

16. Gadoev J, Asadov D, Tillashaykhov M, Tayler-Smith K, Isaakidis P, Dadu A, et al. Factors associated with unfavorable treatment outcomes in new and previously treated TB patients in Uzbekistan: a five year countrywide study. PLoS One. 2015;10(6):e0128907.

17. Sanchez M, Bartholomay P, Arakaki-Sanchez D, Enarson D, Bissell K, Barreira $D$, et al. Outcomes of TB treatment by HIV status in national recording systems in Brazil, 2003-2008. PLoS One. 2012;7(3):e33129.

18. Bustamante-Montes LP, Escobar-Mesa A, Borja-Aburto VH, Gomez-Munoz A, Becerra-Posada F. Predictors of death from pulmonary tuberculosis: the case of Veracruz. Mexico Int J Tuberc Lung Dis. 2000;4(3):208-15.

19. Alavi-Naini R, Moghtaderi A, Metanat M, Mohammadi M, Zabetian M. Factors associated with mortality in tuberculosis patients. J Res Med Sci. 2013;18(1):52-5.

20. Baker MA, Harries AD, Jeon CY, Hart JE, Kapur A, Lonnroth $\mathrm{K}$, et al. The impact of diabetes on tuberculosis treatment outcomes: a systematic review. BMC Med. 2011;9:81.

21. Leung CC, Yew WW, Chan CK, Chang KC, Law WS, Lee SN, et al. Smoking adversely affects treatment response, outcome and relapse in tuberculosis. Eur Respir J. 2015:45(3):738-45.

22. Squire SB, Ramsay AR, van den Hof S, Millington KA, Langley I, Bello G, et al. Making innovations accessible to the poor through implementation research. Int J Tuberc Lung Dis. 2011;15(7):862-70.

23. Lonnroth K, Jaramillo E, Williams BG, Dye C, Raviglione M. Drivers of tuberculosis epidemics: the role of risk factors and social determinants. Soc Sci Med. 2009:68(12):2240-6

24. Bamrah S, Yelk Woodruff RS, Powell K, Ghosh S, Kammerer JS, Haddad MB Tuberculosis among the homeless, United States, 1994-2010. Int J Tuberc Lung Dis. 2013;17(11):1414-9.

25. Haddad MB, Wilson TW, ljaz K, Marks SM, Moore M. Tuberculosis and homelessness in the United States, 1994-2003. JAMA. 2005;293(22): 2762-6.

26. Story A, Murad S, Roberts W, Verheyen M, Hayward AC. London Tuberculosis Nurses Network. Tuberculosis in London: the importance of homelessness, problem drug use and prison. Thorax. 2007;62(8):667-71.

27. Gupta V, Sugg N, Butners M, Allen-White G, Molnar A. Tuberculosis among the homeless-preventing another outbreak through community action. N Engl J Med. 2015;372(16):1483-5.

28. Nava-Aguilera E, Andersson N, Harris E, Mitchell S, Hamel C, Shea B, et al. Risk factors associated with recent transmission of tuberculosis: systematic review and meta-analysis. Int J Tuberc Lung Dis. 2009;13(1):17-26.

29. Figueroa-Munoz Jl, Ramon-Pardo P. Tuberculosis control in vulnerable groups. Bull World Health Organ. 2008;86(9):733-5.

30. National Institute for Health and Care Excellence-NICE. Tuberculosis in vulnerable groups. 2013. https://www.nice.org.uk/advice/lgb11/resources/ tuberculosis-in-vulnerable-groups-60521141388229. Acessed 20 Aug 2014.

31. Burki T. Tackling tuberculosis in London's homeless population. Lancet. 2010:376(9758):2055-6

32. São Paulo State - Department of Health. Brazil. Center for Disease Control (CCD). Tuberculosis Division. http://www.cve.saude.sp.gov.br/tuberculose/. Accessed 15 Nov 2015.

33. Hino P, Villa TC, da Cunha TN, dos Santos CB. Spatial patterns of tuberculosis and its association with living conditions in the city of Ribeirao Preto in the state of Sao Paulo. Cien Saude Colet. 2011;16(12):4795-802.

34. Hino P, Cunha TN, Villa TC, Santos CB. Profile of new cases of tuberculosis in Ribeirao Preto, Sao Paulo State, in the period of 2000 to 2006. Cien Saude Colet. 2011;16 Suppl 1:1295-301. 
35. Martinez VN, Komatsu NK, De Figueredo SM, Waldman EA. Equity in health: tuberculosis in the Bolivian immigrant community of Sao Paulo. Brazil Trop Med Int Health. 2012;17(11):1417-24.

36. Touso MM, Popolin MP, Crispim Jde A, Freitas IM, Rodrigues LB, Yamamura M, et al. Social stigma and the families of patients with tuberculosis: a study based on cluster and multiple correspondence analysis. Cien Saude Colet. 2014;19(11):4577-86

37. Yamamura M, Santos Neto M, Freitas IM, Rodrigues LB, Popolin MP, Uchoa SA, et al. Tuberculosis and social inequity in health: an ecological study using multivariate statistical techniques, Sao Paulo, Brazil. Rev Panam Salud Publica. 2014;35(4):270-7.

38. Ministério da Saúde (Brasil). Secretaria de Vigilância em Saúde. Departamento de Vigilância Epidemiológica: Manual de recomendações para o controle da tuberculose no Brasil. 2011. http://www.cve.saude.sp.gov.br/htm/TB/mat_tec/ manuais/MS11_Manual_Recom.pdf. Accessed 10 Jun 2014

39. Sao Paulo Foundation for Data Analysis-SEADE: São Paulo State Population Features. http://www.seade.gov.br. Accessed 10 Jun 2014

40. Cantalice Filho JP. Food baskets given to tuberculosis patients at a primary health care clinic in the city of Duque de Caxias, Brazil: effect on treatment outcomes. J Bras Pneumol. 2009;35(10):992-7.

41. World Health Organization-WHO. Definitions and reporting framework for tuberculosis - 2013 revision (updated December 2014). Geneva, Switzerland: WHO Publications; 2013. p. 1-47.

42. Mitruka K, Winston CA, Navin TR. Predictors of failure in timely tuberculosis treatment completion, United States. Int J Tuberc Lung Dis. 2012;16(8):1075-82.

43. Sharma SK, Mohan A, Sharma A, Mitra DK. Miliary tuberculosis: new insights into an old disease. Lancet Infect Dis. 2005;5(7):415-30.

44. Galesi VM. Data on tuberculosis in the state of São Paulo, Brazil. Rev Saude Publica. 2007;41 Suppl 1:121.

45. Fleiss JL, Tytun A, Ury HK. A simple approximation for calculating sample sizes for comparing independent proportions. Biometrics. 1980;36(2):343-6.

46. Sterne JA, White IR, Carlin JB, Spratt M, Royston P, Kenward MG, et al. Multiple imputation for missing data in epidemiological and clinical research: potential and pitfalls. BMJ. 2009:338:b2393.

47. Bernaards CA, Belin TR, Schafer JL. Robustness of a multivariate normal approximation for imputation of incomplete binary data. Stat Med. 2007;26(6):1368-82.

48. Rubin DB. Multiple imputation for nonresponse in surveys. New York: Wiley; 1987.

49. Kizuki M, Takano $T$, Nakamura $K$, Fukuda $Y$, Watanabe $M$, Inose $T$, et al. Social course patterns of urban dwellers with tuberculosis under fragile living conditions in Tokyo. Japan J Epidemiol. 2006:16(4):167-75.

50. Borgdorff MW, Veen J, Kalisvaart NA, Broekmans JF, Nagelkerke NJ. Defaulting from tuberculosis treatment in The Netherlands: rates, risk factors and trend in the period 1993-1997. Eur Respir J. 2000;16(2):209-13.

51. Driver CR, Matus SP, Bayuga S, Winters Al, Munsiff SS. Factors associated with tuberculosis treatment interruption in New York City. J Public Health Manag Pract. 2005;11(4):361-8.

52. Siemion-Szczesniak I, Kus J. Impact of social risk factors on treatment outcome in patients with culture positive pulmonary tuberculosis (CPPTB) Pneumonol Alergol Pol. 2012;80(5):412-21.

53. Baussano I, Pivetta E, Vizzini L, Abbona F, Bugiani M. Predicting tuberculosis treatment outcome in a low-incidence area. Int J Tuberc Lung Dis. 2008;12(12):1441-8.

54. Cayla JA, Caminero JA, Rey R, Lara N, Valles X, Galdos-Tanguis $H$, et al. Current status of treatment completion and fatality among tuberculosis patients in Spain. Int J Tuberc Lung Dis. 2004;8(4):458-64.

55. Soza Pineda NI, Pereira SM, Barreto ML. Dropout from tuberculosis treatment in Nicaragua: the results of a comparative study. Rev Panam Salud Publica. 2005;17(4):271-8

56. Villa L, Trompa IM, Montes FN, Gomez JG, Restrepo CA. Analysis of mortality caused by tuberculosis in Medellin, Colombia, 2012. Biomedica. 2014;34(3):425-32.

57. Brewer TF, Heymann SJ, Krumplitsch SM, Wilson ME, Colditz GA, Fineberg HV. Strategies to decrease tuberculosis in us homeless populations: a computer simulation model. JAMA. 2001;286(7):834-42.

58. LoBue PA, Cass R, Lobo D, Moser K, Catanzaro A. Development of housing programs to aid in the treatment of tuberculosis in homeless individuals: a pilot study. Chest. 1999;115(1):218-23
59. Tankimovich M. Barriers to and interventions for improved tuberculosis detection and treatment among homeless and immigrant populations: a literature review. J Community Health Nurs. 2013;30(2):83-95.

60. Nyamathi AM, Christiani A, Nahid P, Gregerson P, Leake B. A randomized controlled trial of two treatment programs for homeless adults with latent tuberculosis infection. Int J Tuberc Lung Dis. 2006;10(7):775-82.

61. Tulsky JP, Pilote L, Hahn JA, Zolopa AJ, Burke M, Chesney M, et al. Adherence to isoniazid prophylaxis in the homeless: a randomized controlled trial. Arch Intern Med. 2000;160(5):697-702.

62. Tulsky JP, Hahn JA, Long HL, Chambers DB, Robertson MJ, Chesney MA, et al. Can the poor adhere? Incentives for adherence to TB prevention in homeless adults. Int J Tuberc Lung Dis. 2004;8(1):83-91.

63. Kawatsu L, Sato N, Ngamvithayapong-Yanai J, Ishikawa N. Leaving the street and reconstructing lives: impact of DOTS in empowering homeless people in Tokyo, Japan. Int J Tuberc Lung Dis. 2013:17(7):940-6.

64. French CE, Kruijshaar ME, Jones JA, Abubakar I. The influence of socio-economic deprivation on tuberculosis treatment delays in England, 2000-2005. Epidemiol Infect. 2009;137(4):591-6.

65. Jimenez-Fuentes MA, Auge CM, Gomez MN, Peiro JS, de Souza Galvao ML, Maldonado J, et al. Screening for active tuberculosis in high-risk groups. Int J Tuberc Lung Dis. 2014;18(12):1459-65.

66. Nery JS, Pereira SM, Rasella D, Penna ML, Aquino R, Rodrigues LC, et al. Effect of the Brazilian conditional cash transfer and primary health care programs on the new case detection rate of leprosy. PLoS Negl Trop Dis. 2014;8(11):e3357.

67. Carneiro Jr N, de Jesus $\mathrm{CH}$, Crevelim MA. The family health strategy focused on access equity and targeted at the homeless population living in large urban centers. Saude e Sociedade. 2010;19(3):709-16.

68. Sagbakken M, Frich JC, Bjune GA, Porter JD. Ethical aspects of directly observed treatment for tuberculosis: a cross-cultural comparison. BMC Med Ethics. 2013:14:25

\section{Submit your next manuscript to BioMed Central and we will help you at every step:}

- We accept pre-submission inquiries

- Our selector tool helps you to find the most relevant journal

- We provide round the clock customer support

- Convenient online submission

- Thorough peer review

- Inclusion in PubMed and all major indexing services

- Maximum visibility for your research

Submit your manuscript at www.biomedcentral.com/submit 